\title{
Brazil has the talent: just let us get on with the job
}

\section{Frustrated researchers are calling for support from the international scientific community.}

Sir - Unlike Europe or the United States, where the demand for people with PhDs is relatively low in the scientific market, Brazil still needs these $\mathrm{PhDs}$ in research positions, mainly in the universities, which nowadays are seriously understaffed. Yet we have a dramatic problem, in that these posts are not being filled.

Brazil has a population of nearly 169 million people, about $0.02 \%$ of whom have doctorates. A large part of its scientific research is done in the 52 federal universities, supported by the national government.

The country currently lacks teachers and researchers. Areas such as ecology, sociology, economy, history and engineering require applied as well as basic research to address urgent national problems. However, no academic positions have been offered since a governmental decree was passed in November 1997, putting a freeze on both filling and creating research positions. Since then, no new permanent positions have been created, and even those that were already planned have been cancelled, jeopardizing public universities and basic research.

This government policy means that a whole generation of young $\mathrm{PhDs}$ will be lost to research. Between 1998 and 1999, for example, only 1,481 new doctors were added to the staff of the county's 52 federal universities, even though 8,790 Brazilian students obtained a $\mathrm{PhD}$ during this period.

These young doctors are the result of decades of investment on the part of the Brazilian government; some have obtained $\mathrm{PhDs}$ in the world's best scientific centres. Each of these students costs Brazil about US $\$ 22,680$ per year if they study abroad, and $\$ 7,250$ per year if they study in this country. According to the Brazilian Council for Scientific and Technological Development (CNPq), Brazil spent $\$ 65,631,910$ in 1998 , and $\$ 38,708,594$ in 1999 (a significantly lower investment than the previous year) on grants.

This is the first time that so many welltrained scientists are available to work in Brazil, with the potential to fulfil the needs of our country in various scientific areas. They were intended to enhance Brazil's position in international science, and to open opportunities for collaborative enterprises.

After several protests at the beginning of this year, and long negotiations with the universities, the Brazilian government seemed to be willing to improve the situation. But the position has gone back and forth since then - on 20 March the government prohibited the creation of any new positions in the federal universities, even temporary contracts. Then, having come under pressure from the federal universities' rectors, the government backtracked and renewed its promise to create 2,000 emergency positions (of the 6,000 needed). But nothing has yet happened.

Brazil's scientific community lacks the political strength to make its protests heard. Therefore, we have decided to mobilize our community to show the government that there is public interest in the development of science in Brazil, and that there is also a qualified workforce available to help our country to overcome its social and economic problems.
Readers interested in supporting our efforts are asked to contact S.P.R. by e-mail at serviopr@mono.icb.ufmg.br. Sérvio P. Ribeiro*, Milton de S. MendonçaJúnior†, Edésio M. Barbosa $\ddagger$, J. Adauto de Souza Neto $\S$

${ }^{\star}$ Departamento de Biologia Geral/ICB, Universidade Federal de Minas Gerais, CP 484 30161-970, Belo Horizonte, Minas Gerais, Brazil $\dagger$ Laboratório de Ecologia de Insetos, Departamento de Zoologia, UFRGS, Av. Bento Gonçalves, 9500, CEP 91501-970, Porto Alegre, Rio Grande do Sul, Brazil

$\ddagger L E M$ - Laboratoire Environnement et Minéralurgie 15, Avenue du Charmois BP40 F-54501, Vandoeuvre-Les-Nancy Cedex, France $\$$ Departamento de Geologia, Centro de Ciências Exatas e da Terra, UFRN, Lagoa Nova, CEP 59.072-970, Natal, Rio Grande do Norte, Brazil

\section{Group did give timely foot-and-mouth analysis}

Sir - We write to correct some factual inaccuracies in the Correspondence by R. G. Eddy (Nature 412, 477; 2001), which itself was a response to your Opinion article "Lessons from an epidemic" (Nature 411, 977; 2001).

Eddy suggests that the Imperial College group did not make the details of their research on models of foot-andmouth virus transmission available to stakeholders until the publication of our paper in Science on 12 April. This is incorrect: we sent details of our preliminary analyses to the UK chief veterinary officer on 16 March.

In addition, we were the only group to present - on 23 March - a detailed analysis of the epidemic and potential control options to stakeholders including officials from the UK's Ministry of Agriculture, Fisheries and Food (now the Department for Environment, Food and Rural Affairs), the Office of Science and Technology and the Food Standards Agency. Our presentation included details of the modelling techniques we used.

Since then, we have regularly presented new, updated results to the UK chief scientist's foot-and-mouth disease advisory group (which includes teams from Edinburgh, Cambridge and Pirbright), and have had several discussions with the Royal Society and the National Farmers' Union.

Roy M. Anderson, Neil M. Ferguson, Christl A. Donnelly
Department of Infectious Disease Epidemiology, Faculty of Medicine, Imperial College of Science, Technology and Medicine, London W2 1PG, UK

\section{To boldly go where no plant has yet been found}

Sir - US funding agencies' call for ocean exploration should lead to exciting discoveries, with light being shed on some of the least known portions of our biosphere. But contrary to the details given in the News feature "To boldly go" (Nature 412, 672-673; 2001), scientists involved in the study of Blake Ridge methane seeps have no intention of studying plant life supported by methane at 2,000 metres.

Sunlight penetrates only a few hundred metres into the water column. Although there has been speculation that light generated by thermal radiation from deep-sea hot springs might be sufficient to sustain facultative photoheterotrophic bacteria, the Blake Ridge seeps have no thermal source of light. It would be a surprise, indeed, to discover multicellular plants living in 2,000 metres of water anywhere in the oceans.

Cindy Lee Van Dover

Biology Department, College of William \& Mary, P. O. Box 8795, Williamsburg, Virginia 23187, USA

The author intended to say that the researchers would study any life that exists around the Blake Ridge methane seeps. The phrase "plant life" was incorrectly introduced during editing Correspondence Editor, Nature 